\title{
Psychotic Disorders hospitalizations associated to cannabis abuse or dependence: A Nationwide Study
}

Manuel Gonçalves-Pinho a,b | Miguel Bragança ${ }^{c} \mid$ Alberto Freitas a,b

Corresponding Author: Manuel Gonçalves-Pinho| manuelpinho19@gmail.com

Rua Dr. Plácido da Costa, 4200 - 450 Porto, Portugal | +351 225513622

a Department of Community Medicine, Information and Health Decision Sciences, Faculty of Medicine, University of Porto, Porto, Portugal

${ }^{b}$ Center for Health Technology and Services Research (CINTESIS), Porto, Portugal

Department of Clinical Neurosciences and Mental Health, Faculty of Medicine, University of Porto, Porto, Portugal

\section{OBJECTIVES}

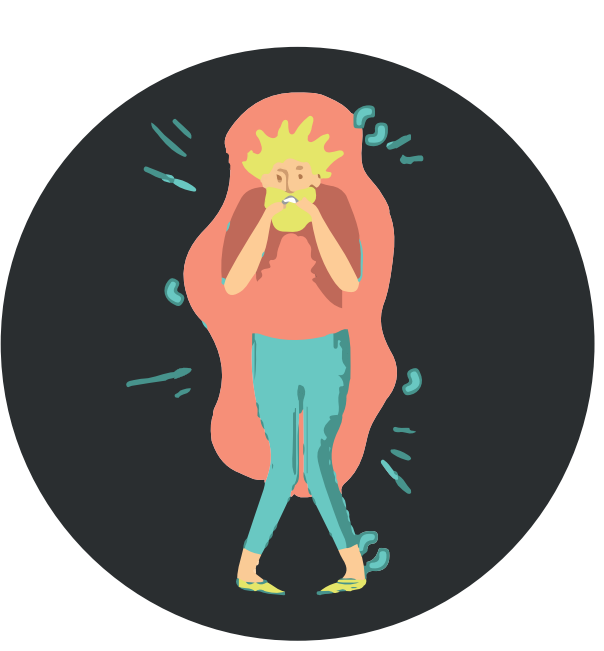

We aimed to describe and correlate the hospital panorama of Psychotic disorders (PD)

with Cannabis Use (CU) trends in Portuguese public hospitals.

\section{BACKGROUND}

Cannabis abuse or dependence is linked to higher and earlier incidence of PD.

Hospitalizations related to CU and PD represent an important indicator of the burden that cannabis consumption may impose ${ }^{1-4}$

\section{MATERIALS AND METHODS}

We conducted a retrospective observational study that analysed all hospitalizations that occurred in Portuguese public hospitals from the year 2000 to 2015. Hospitalizations with a primary diagnosis of PD or Schizophrenia were selected based on CCS (Clinical Classification Software) diagnostic single-level 659. Episodes associated to CU were identified by the ICD-9-CM code 304.3/305.2 that correspond to Cannabis dependence/Cannabis abuse.

\section{RESULTS}

The number of hospitalizations with a primary diagnosis of PD and Schizophrenia with associated CU rose 29.4 times during the study period, from 20 to 588 hospitalizations yearly (2000 and 2015 respectively) with a total of 3233 hospitalizations. Male patients represented $89.8 \%$ of all episodes and the mean/median age at discharge were $30.66 / 29.00$ years, respectively. From all hospitalizations with a primary diagnosis of PD or schizophrenia the percentage with a secondary diagnosis of CU rose from $0.87 \%$ in 2000 to $10.60 \%$ in 2015 . (Table 1)

\begin{tabular}{|c|c|c|c|c|c|c|}
\hline Year & $\begin{array}{c}\text { Hospitalization } \\
\text { episodes due to } \\
\text { PD with associated } \\
\text { CU (n=) }\end{array}$ & $\begin{array}{l}\text { \% from all Schizophrenia } \\
\text { Schizophrenia and other } \\
\text { psychotic disorders } \\
\text { hospitalizations }\end{array}$ & $\begin{array}{l}\text { Hospitalizations per } \\
100,000 \text { inhabitants }\end{array}$ & $\begin{array}{c}\text { Mean Age + SD } \\
\text { (years) }\end{array}$ & Male sex $(\% / n)$ & $\begin{array}{l}\text { Mean/Median } \\
\text { LoS (days) }\end{array}$ \\
\hline 2000 & 20 & 0.87 & 0.19 & $24.40+5.64$ & $90.0 / 18$ & 19.45 / 9.50 \\
\hline 2001 & 24 & 0.91 & 0.23 & $27.79+7.72$ & 91.7 / 22 & $21.83 / 20.00$ \\
\hline 2002 & 41 & 1.53 & 0.39 & $27.29+5.87$ & $97.6 / 40$ & $21.71 / 20.00$ \\
\hline 2003 & 61 & 1.75 & 0.58 & $26.90+7.23$ & 82.0 / 50 & $21.97 / 19.00$ \\
\hline 2004 & 75 & 2.08 & 0.71 & $28.56+11.15$ & 88.0 / 66 & $29.19 / 21.00$ \\
\hline 2005 & 99 & 2.72 & 0.94 & $27.57+7.41$ & 91.9 / 91 & $30.21 / 20.00$ \\
\hline 2006 & 82 & 2.23 & 0.78 & $26.99+8.79$ & 90.2 / 74 & $23.67 / 19.50$ \\
\hline 2007 & 93 & 2.43 & 0.88 & $27.67+8.24$ & $94.6 / 88$ & $20.66 / 16.00$ \\
\hline 2008 & 190 & 3.69 & 1.80 & $30.24+8.06$ & $90.5 / 172$ & $15.87 / 11.00$ \\
\hline 2009 & 185 & 3.51 & 1.75 & $29.65+8.20$ & 92.4 / 171 & $15.77 / 12.00$ \\
\hline 2010 & 211 & 4.11 & 2.00 & $30.86+9.17$ & $89.6 / 189$ & $17.03 / 12.00$ \\
\hline 2011 & 259 & 4.98 & 2.46 & $30.58+9.63$ & $91.1 / 236$ & 18.08 / 16.00 \\
\hline 2012 & 320 & 5.87 & 3.05 & $31.49+9.64$ & 88.1 / 282 & $19.25 / 14.50$ \\
\hline 2013 & 453 & 8.28 & 4.34 & $31.55+9.48$ & 88.7 / 402 & $19.06 / 14.00$ \\
\hline 2014 & 532 & 9.60 & 5.13 & $31.59+9.44$ & 89.8 / 478 & $18.08 / 15.00$ \\
\hline 2015 & 588 & 10.60 & 5.69 & $24.40+5.64$ & 88.9 / 523 & $20.37 / 16.00$ \\
\hline Total & 3233 & 4.71 & N.A & $30.66+9.30$ & $89.8 / 2902$ & $19.42 / 15.00$ \\
\hline
\end{tabular}

Table 1 - Hospitalizations associated with Cannabis Use and a primary diagnosis of Psychotic Disoder or Schizophrenia

\section{CONCLUSIONS}

PD and Schizophrenia hospitalizations linked to CU rose between 2000 and 2015. Patterns of consumption may explain the results found in this study, the increasing frequency of moderate/high dosage cannabis consumers is one of the possible explanations for the higher number of hospitalizations and increasing hospitalization rate per 100,000 inhabitants.
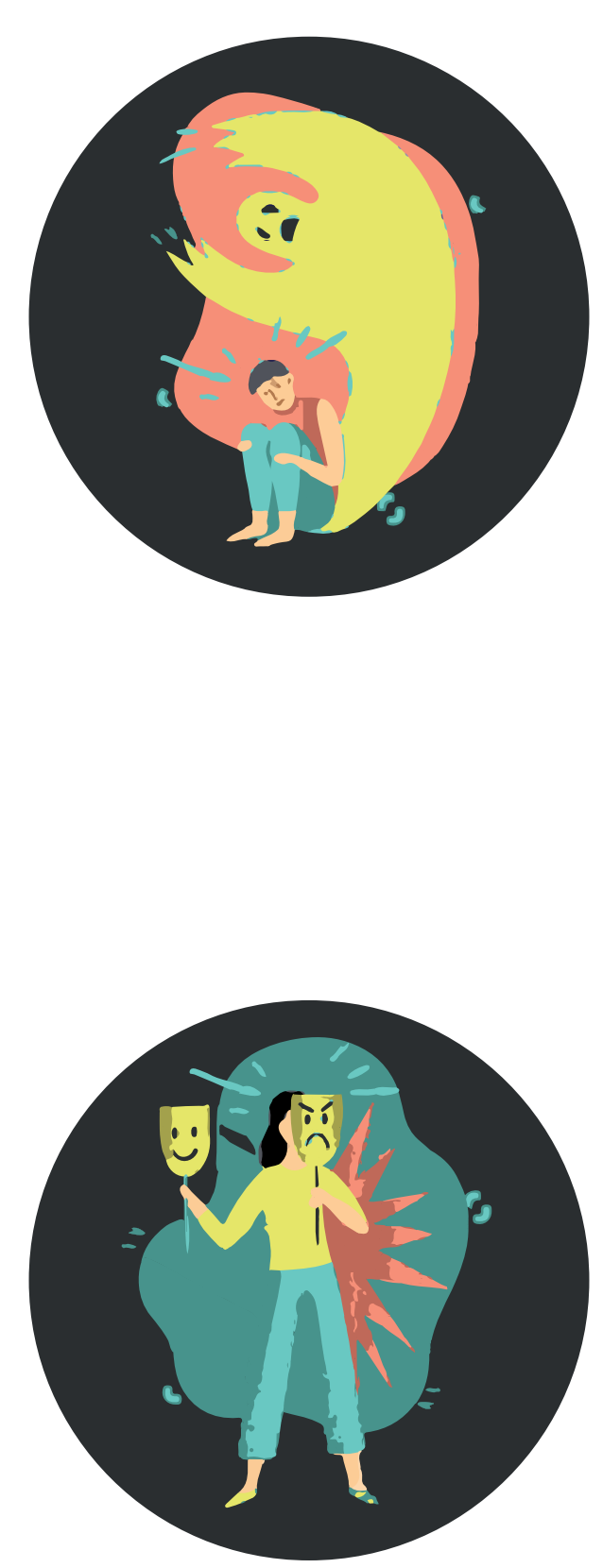

References

Andreasson, S., Allebeck, P. Engstrom, A., \& Rydberg, U. (1987) Cannabis and schizophrenia. Congitudinalstudy of Swe dish conscripts. Lancet, 2(8574), 1483 1486

| Anual, R. (2014). A Situação do País em Matéria de Drogas e oxicodependências. Serviço de intervenção nos Comportamentos e nas Dependências: Divisão de Estatística e Investigação e Divisão de Informação e Comunicação. Lisboa

3 | Carliner, H., Brown, Q. Sarvet, A. L. \& Hasin, D. S. (2017). Cannabis use attitudes, and lega status in the U.S.: A review Prev Med, 104, 13-23 doi:10 1016/jypmed.2017.07.008

4 I Charilaou, P., Agnihotri, K. Garcia, P., Badheka, A., Frenia, D. \& Yegneswaran, B. (2017). Trends of Cannabis Use Disorder in the inpatient: 2002 to 2011 . Am J Med 30(6), 678-687.e677. doi:10.1016/.amjmed.2016.12.035 